\title{
Performances of two commercially available Newcastle disease vaccines in Bangladesh: A case-control study
}

\author{
MAKashem ${ }^{1 *}$, M A Hashem², M H B. Kabir 1 , M I Uddin ${ }^{3}$ and B Hasan ${ }^{4}$ \\ ${ }^{1}$ Department of Microbiology, Faculty of Veterinary Medicine, Chittagong Veterinary and Animal Sciences University (CVASU), Khulshi-4202, \\ Chittagong, Bangladesh, ${ }^{2}$ Veterinary Surgeon, Chittagong City Corporation, Chittagong, ${ }^{3}$ Poultry Research and Training Centre, CVASU, Khulshi- \\ 4202, Chittagong, Bangladesh, ${ }^{4}$ Section of Infectious Diseases, Department of Medical Sciences, Uppsala University, SE - 75185 Uppsala, Sweden.
}

(Received 22 May 2011; Accepted 22 October 2011)

\begin{abstract}
The study was conducted to test the performances of two commercially available live vaccines named BCRDV1 (VG/GA strain) and BCRDV2 (F-strain). A total of 90 day-old broiler birds were divided into three different groups and the serum samples were collected at day 1, 7, 14, 21, 28 and 35; mean \pm SD of Haemgglutination Inhibition (HI) titres $\left(\log _{2}\right)$ were found as $8 \pm 0.00,7.2 \pm 0.89,6.1 \pm 0.9,7.1 \pm 0.75,5.7 \pm 0.72,4.1 \pm 0.68$ and $8 \pm 0.00$, $6.0 \pm 0.76,4.8 \pm 0.81,5.8 \pm 0.83,4.9 \pm 0.86,3.8 \pm 0.77$ in group I and group II respectively, which was significant $(\mathrm{P}<$ 0.01 ). In control (group III) the mean $\pm S D$ was found to be $8 \pm 0.00,5.8 \pm 0.87,4.9 \pm 0.69,4.1 \pm 0.48,3.0 \pm 0.56$ and $<2 \pm 0$ respectively. The titres of control group infer that the maternal antibody usually had a tendency to decline and may pose a risk of infection. In protection test, $\mathbf{1 0 0 \%}$ mortality were found in control group (III) but in group I and group II the mortality of birds were $6.67 \%$ and $10 \%$, respectively. The analysis of $\mathrm{HI}$ titres with the target to determine the performance of two vaccines revealed that BCRDV1 vaccinated groups was able to maintain significantly higher HI titres than BCRDV2 vaccinated group.
\end{abstract}

Key Words: BCRDV, HI test, Newcastle disease, Broiler birds

Newcastle disease (ND) is one of the serious viral diseases of commercial poultry and responsible economic loses in the poultry industry. Though this disease was first recorded in UK but this has frequently been recorded recently in USA ${ }^{1}, \mathrm{Canada}^{2}$ and France $^{3-4}$. Even in Asian countries like Philippines ${ }^{5}$, Japan ${ }^{6}$ and India $^{7}$, which is a close neighboring country of Bangladesh, are affected with this devastating disease. Newcastle disease is caused by Avian Paramyxovirus serotype-1 (APMV-1) viruses, which belongs to family Paramyxoviridae ${ }^{8}$. The disease is acute and contagious and is characterized by sudden onset and rapid spread within the flock, resulting in high morbidity and mortality. The disease usually occurs in domesticated, wild and caged birds which are susceptible. Furthermore, birds of all ages were found as susceptible to this disease ${ }^{9}$. Inhalation of aerosols is considered to be the primary mode of transmission of NDV within a flock ${ }^{10}$. Approximately two days after exposure and before showing any clinical signs, the infected birds begin to liberate virus in the air that leaves its respiratory tract and continues to do so for several days ${ }^{11}$. Coughing, gasping and disturbances of respiration are not required to generate an infective aerosol but probably enhances its production. Chickens infected with NDV have been used as a source of naturally generated aerosol particles to test efficacy of air filters in removing infections from air $^{12}$. Coughing and sneezing may shed huge quantity of viruses and thus contaminate the chicken coop, equipment and clothing of personnel ${ }^{13}$. In Bangladesh, unexpected death of poultry causes economic loses of farmers and $30 \%$ of the mortality in poultry industry is caused by infectious diseases where ND virus plays an important role ${ }^{14}$. Newcastle disease, popularly known as Ranikhet disease in Bangladesh, considered as one of the most important threats to the poultry industry. ND claimed up to 40$60 \%$ of the total mortality in rural scavenging chickens in late seventies ${ }^{15}$. Routine vaccination is practiced in the country as a means of protection. Therefore, information about the types of vaccine, efficacy of the vaccine and vaccination schedules is very important issues when considered the protection of birds against ND. The types of vaccine and vaccination schedule adopted are influenced by a variety of factors such as, antigenicity of the vaccine given, virulence of the field virus, routes of vaccine administration and age of birds to be vaccinated ${ }^{16}$. Chittagong district is considered as one of the poultry belts in Bangladesh and thousand of poultry farms have established and poultry products from this area contribute as protein sources for the people of Bangladesh. In this study we selected two vaccines such as BCRDV1 (VG/GA strain) and BCRDV2 (F-strain). We selected both BCRDV1 and BCRDV2 based on availability and their low price. Considering the above mentioned factors, the study was undertaken to evaluate the performances of two commercial Newcastle disease vaccines in broiler birds reared under intensive system in Bangladesh. 
The blood samples for this study were collected from three different commercial broiler farms and divided into three groups. The blood samples were stored in refrigerator for 2 to 3 hours in order to separate serum. After clotting of blood, serum was collected from each syringe in an Eppendorf tube ( $1.5 \mathrm{ml}$ capacity) and stored at $-20^{\circ} \mathrm{C}$ for further analysis in the laboratory of Microbiology of Chittagong Veterinary and Animal Sciences University. In case of protection test, birds in three groups were subsequently challenged with virulent field strain velogenic ND virus and result was observed properly. Field samples were preserved as a source of virulent strain of NDV in the Department of Microbiology, CVASU.

All birds were categorized into three different groups; group I marked as vaccinated with BCRDV1 (VG/GA strain), group II as vaccinated with BCRDV2 (F-strain) and group III as a control. Among these groups, samples were collected at the age of days $1,7,14,21,28$ and 35 considering maximum 30 samples in each of three groups. The propagation of virus of the preserved samples was done on 9-10 days old chicken embryo in allantoic cavity. The allantoic fluid was collected and stored at $-20^{\circ} \mathrm{C}$ for analysis. The collected fluid was tested by micro plate Haemagglutination (HA) test for confirming the virulence properties of the virus by following standard method ${ }^{17}$.

Five milliliter of blood was collected in a tube containing anticoagulant from each chicken, which was vaccinated against $\mathrm{ND}$ and free from ND infection. After the blood sample was washed with an equal volume of phosphate-buffered saline (PBS) at $\mathrm{pH}$ 7.0. The supernatant was poured off, and 20 volume of PBS was added into the packed cells and washed twice. The cells were then used to prepare a $1 \%$ suspension based on volume by adding $1 \mathrm{ml}$ of the packed cells to $100 \mathrm{ml}$ of PBS at $\mathrm{pH} 7.0$.

Fifty microlitter of PBS dispended into each well of one row of the plastic V-bottomed 96 well plate. Then $50 \mathrm{ml}$ of virus suspension (Avinew ${ }^{\circledR}$ vaccine, Advance Animal Science Co. Ltd.) was placed into the first well and made two-fold dilutions. A row with control was also made using PBS only instead of virus antigen. This control well was made for showing the normal setting patterns and time of red blood cells in suspension. Then $50 \mathrm{ml}$ of PBS was added to each well (including control wells). Finally, $50 \mathrm{ml}$ of $1 \%$ chicken RBC suspension was added to each well, tilted gently and allowed to stand at room temperature for 45 minutes to stop dehydration. The results of the $8^{\text {th }}$ well were read and recorded to show haemagglutination (thin film) of $1 \mathrm{HA}$ unit. Determination of 4HA unit virus antigen from this HA results was made as described by Ilaria and Alexander ${ }^{18}$.

Fifty microlitter of PBS was dispended into each well of first row of a plastic V-bottomed 96 well plate, and then $50 \mathrm{ml}$ of serum sample from test bird was placed into first well of the plate including control well. Two fold dilutions of $50 \mathrm{ml}$ volumes of serum were made across the plate and same volume of 4HA unit virus were added in each well except the control well. Then it was left for 30 minutes at room temperature $\left(25^{\circ} \mathrm{C}\right)$ and afterwards
$50 \mathrm{ml}$ of $1 \%$ chicken RBC were added to each well including the control one. Following mixing them gently, plate was allowed to settle down for 40 minutes at room temperature. Finally, the result were read, and interpreted only to those wells in which the RBC streams at the same rate as the control wells. This finding was considered as showing inhibition. The validity of results was assessed against a negative control serum, which did not give a titre $>\log _{2}{ }^{4}$. HI titre was regarded as being protective if there was inhibition at serum dilution of $\log _{2}{ }^{4}$ or more against $4 \mathrm{HAU}$ of the NDV used.

Thirty birds from each group were isolated and challenged subcutaneously on the day $35^{\text {th }}$ with a virulent field strain of NDV at a dose rate of $0.1 \mathrm{ml} /$ per bird. The birds were kept under close observation for 19 days to recognize the development of one set of clinical signs. Disease lesions were investigated and recorded through post-mortem examination and further, samples with lesions were used to isolate the virus. Total numbers of dead and live birds were also recorded. The preventable fraction/ protection index to evaluate the efficacy of vaccines was calculated using the previously described method by Tizard ${ }^{19}$. The level of antibody response was analyzed and compared between groups I and II by using a 2-sample t-test for equal variance as described by Steel and Torrie ${ }^{20}$. The value, $\mathrm{P}<0.01$ was considered as significant.

Level of maternally derived antibody (MDA) persists in the broiler birds were determined by haemagglutination inhibition (HI) test from day 1 to day 35 . This study gives emphasis on the evaluation of the performances of two commercially available vaccines; BCRDV1 (VG/GA strain) and BCRDV2 (F strain) that were tested in broiler birds. The results of these tests stated as mean $\pm \mathrm{SD}$ of $\mathrm{HI}$ titres of 30 broiler birds in each age groups (I, II, III) and measured at stages of pre-vaccination (day 1), post-primary (day 7 and 14) and post-secondary (day 21, 28 and 35) vaccination are presented in Table 1.

It was observed that the mean $\pm \mathrm{SD}$ of sera samples of groups I and II were $7.2 \pm 0.89$ and $6.0 \pm 0.76$ respectively on day $7^{\text {th }}$ whereas on day $14^{\text {th }}$ mean titres were $6.1 \pm 0.9$ and $4.8 \pm 0.81$ respectively. Similarly, it was found that on day 21; the mean \pm SD of HI titres of group I and group II were $7.1 \pm 0.75$ and $5.8 \pm 0.83$ respectively. On the following occasion of day 28 and 35 the mean \pm SD of HI titres in group I and II were $5.7 \pm 0.72$ and $4.9 \pm 0.86 ; 4.1 \pm 0.68$ and $3.8 \pm 0.77$ respectively. After the challenge test vaccine gave $93.33 \%$ and $90 \%$ protection in group I and group II, respectively (Table 2). Unvaccinated (control) group was found highly susceptible to challenge as revealed by death of all birds. Birds that died following post-challenge test were examined by postmortem examination. Usually gross lesions were minimal in young or old birds although there were mild air sacculitis, tracheitis and conjunctivitis. The other changes observed were haemorrhagic or necrotic focal lesions in the mucosa of the intestine. 
Table1. Level of HI titre in birds vaccinated with ND vaccine of groups I, II and challenge test compared to unvaccinated group III.

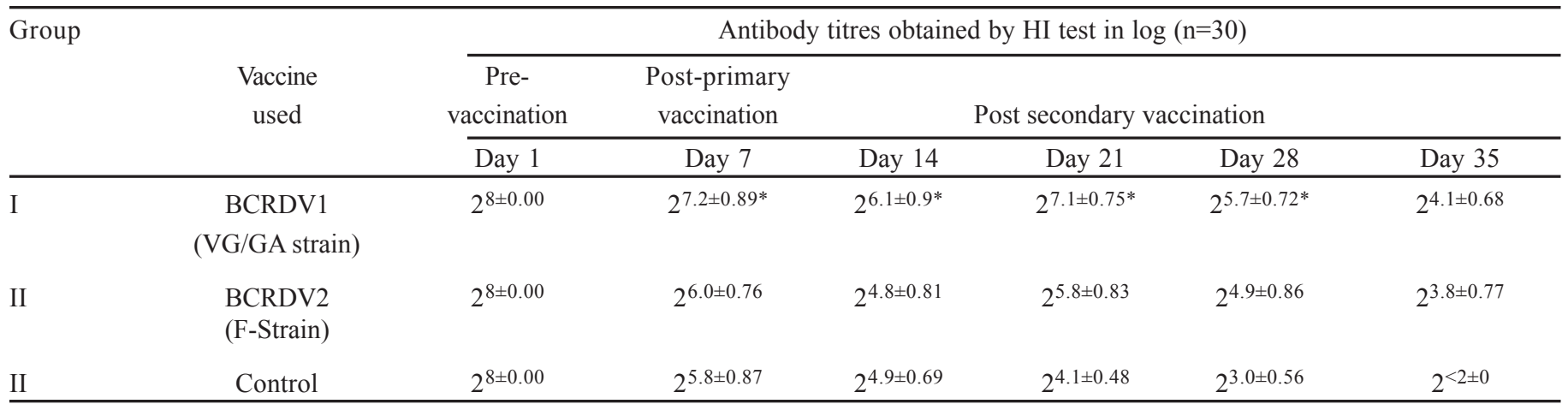

$\mathrm{n}=$ Number of sera samples, $*$ Significant at $\mathrm{p}<0.01$

Table 2. Protection against challenged samples with virulent field strain of velogenic NDV at the age of day 35.

\begin{tabular}{lcccccc}
\hline Groups & Vaccine used & Total birds & Live birds & Dead birds & Mortality (\%) & Preventable fraction (PF) \\
\hline I & BCRDV1 (VG/GA strain) & 30 & 29 & 2 & 6.67 & 93.33 \\
II & BCRDV2(F-Strain) & 30 & 28 & 3 & 10 & 90 \\
II & Control & 30 & 0 & 30 & 100 & - \\
\hline
\end{tabular}

Study revealed that maternally derived antibody remained till the age of day $28^{\text {th }}$ but in minimal level, and then gradually disappeared and became completely absent after the age of day $28^{\text {th }}$ or onward. From our study it can be stated that the newly hatched chicks usually have a high level of maternal antibody declined to zero in chicks after the age of 25 days. However, in previous studies researchers reported that maternally derived antibody persist and remained protective until the age of $12^{\text {th }}$ days ${ }^{15}, 17^{\text {th }}$ days ${ }^{21}$ and 18 days $^{22}$ in chicks. The level of HI antibody titres exists during first two weeks of life ${ }^{23-24}$. According to Islam et al. ${ }^{25}$, maternally derived antibody can be considered as an effective means of protection of the chickens till two weeks of age.

According to the findings of present study, the HI titres of group I showed fairly higher than group II those were vaccinated with BCRDV1 and BCRDV2 respectively, which is in line with the previous work done by Beard et al. ${ }^{26}$ who stated VG/GA strain produced better immunity than $\mathrm{B} 1$. It is also similar to the findings of Mahmud ${ }^{27}$ who stated that the mean HI titre was higher in birds vaccinated with Avinew ${ }^{\circledR}$ (VG/GA strain) than BCRDV (Fstrain). When we tested the protective ability of the host on the basis of post-challenge mortality at day 35 , it was found that mortality to the challenges host is higher in group II (10\%) than group I $(6.67 \%)$. We treated the group III as a control (unvaccinated) and found that the level of HI titres gradually decreases day by day. Similarly, birds of control group showed $100 \%$ mortality and inference was made that the unvaccinated group fully susceptible to the disease, because the level of MDA was too low to protect the birds (unvaccinated) against ND. This finding highlighted that the birds vaccinated with BCRDV1 had 93.33\% protection, although $\mathrm{HI}$ antibodies titers were low. It's also found that the minimum $\mathrm{HI}$ titre to resist challenge infection was 4 or even more ${ }^{28}$. Lower mortality in BCRDV1 vaccinated birds were also reported by Al-Garib et al. ${ }^{29}$. Vaccination is extensively used to protect birds against Newcastle disease (ND). During vaccination emphasis were given to some important factors for successful vaccination such as the efficacy of the vaccines used, types of vaccine available, route of administration, antigenicity of vaccine virus, age of birds and vaccination schedule etc. Vaccination is an effective control measure which relies on two aspects. Firstly, vaccination of the parent stock to ensure that the progeny chicks are hatched with a high level of maternally-derived antibody (MDA) and secondly, vaccination of the chickens with a suitable vaccine at the correct age. The resultant high level of MDA found in the progeny chickens is important in protecting the chicken during 10 to 14 days of age from NDV infection ${ }^{30}$.

From the above discussion it can be concluded that birds with BCRDV1 vaccine had more protective effects than BCRDV2. There is no remarkable difference found between the protective index of group I and group II, but significant differences was observed in the HI antibody titer between two groups. Therefore, BCRDV1 and BCRDV2 can be recommended for an effective ND control program under intensive conditions but BCRDV1 vaccine can be made much more preferable for protection of birds against Newcastle disease. The study suggests further investigation for more effective output about the performances of available BCRDV.

\section{Acknowledgement}

The author would like to express thanks to the farmers for their kind help and valuable information to make this study successful.

\section{References}

1. Minard EL and Jungherr E. 1944. Neutralization tests with avian pneumoencephalitis virus. Am J Vet Res 5: 154-57.

2. Walker RVL. 1948. Newcastle disease. Can J Comp.Med Vet Sci. 12: 172-76. 
3. Lissot G. 1956. Peste aviaire, variete maladie de Newcastle, a virus faible. Bull. Acad Vet France. 29: 43-45.

4. Fontaine MP, Fontaine C, Chabas D and Brain AJ. 1965. Presence of a Newcastle disease-like virus against in chicken embryo cells. Avain Diseases. 9: 1-7.

5. Farinas EC. 1930. Avian pest, a disease of birds hitherto unknown in the Philippine Islands. Philippine J Agr. 1: 311-66.

6. Kawashima HT, Sato and Hanaki T. 1953. The latest outbreak of Newcastle disease in Japan. Rept Govt Exp Sta Animal Hyg (Japan). 27: 151-67.

7. Edwards JT. 1928. A new fowl disease. Ann Rept Imp Inst Vet Res. pp $14-15$.

8. Alexander DJ. 1988. Newcastle disease. In: Alexander, D.J. (Ed), Methods of spread, Kluwer Academic publishers, Boston, pp: 256272.

9. American Poultry Association. Newcastle disease. Available at: http:/ /www.amerpoultryassn.com/respiratory_disease.htm

10. Hanson RP. 1988. Heterogenicity within strains of Newcastle disease virus, Key to survival. In D.J. Alexander ed. Newcastle Disease. Kluwer Academic Publishers, Boston, MA, pp. 113-130.

11. Lancaster JE and Alexander DJ. 1975. Newcastle disease virus and spread. Monograph No. 11 Canada Department of Agriculture, Ottawa, pp. 73.

12. Hopkins SR and Drury LN. 1971. Avian Dis. 15: 596-603.

13. Chakrabarti A. 1989. Practice of Poultry Medicine, kalyani Pub. Ludhiana. Doyle, TM and Wright. EC, 1950. An inactivated vaccine against Newcastle disease. British Vet. 106: 36-61.

14. Ali MJ. 1994. Current status of Veterinary Biologics Production in Bangladesh and their quality control. Proceedings of the BSVER symposium used in July 28, 1994 at NIPSOM auditorium, Mohakhali, Dhaka, Bangladesh.

15. Chowdhury TIMFR, Sarker AJ, Amin MM and Hossain WIMA. 1982. Studies of Newcastle disease in Bangladesh. Vet J. 15: 1-9.

16. Allan WH, Lancaster JE and Tooth B. 1978. Newcastle disease vaccines, their production and use. Food and Agricultural Organization (FAO) of Animal Production series No. 10 FAO. Rome, pp. 163.

17. OIE (Office International des Epizootics) Terrestrial Manual 2009. Newcastle disease. Chapter- 2.3.14: 576-589.

18. Ilaria C and Alexander DJ. 2009. Haemagglutination test in Microtitre plates (Micro HA test. Avian influenza and Newcastle disease: A field and laboratory manual. Chapter: 7.2.3.1: 76-77.
19. Tizard IR. 2004. Veterinary Immunology: An Introduction; 7th Ed., W.B. Saunders Company, Philadelphia. pp. 263-264.

20. Steel RGD and Torrie JH. 1982. Principles and Procedures of Statistics, 2nd Ed., McGraw-Hill Book Co. Inc., New York. pp. 137-171.

21. Saeed Z, Ahmad S, Rizvi AR and Ajmal M. 1988. Role of maternal antibody in determination of an effective Newcastle disease vaccination programme. Pak $J$ of Vet Res. 1: 18-21.

22. Shil NC. 2006. Evaluation of the antibody production following single vaccination with BCRDV, Izovac B1 Hitchner ${ }^{\circledR}$ and Cevac New L ${ }^{\circledR}$ in broiler chicks. MS Thesis. Department of Microbiology and Hygiene, Bangladesh Agricultural University (BAU), Mymensingh.

23. Begum K, Khan MSR, Rahman MB, Kafi MA, Das M and Mamun SAA. 2006. Investigation on baby chick Ranikhet disease vaccine administration in chicks of vaccinated and nonvaccinated origin. Bang J Vet Med. 4(2): 93-96.

24. Ibrahim AL, Ideris A and Babjee AM. 1992. An overview of the use food based Newcastle disease vaccine in Malaysia. In Newcastle Disease in Village Chickens, pp. 75-78. Australian Centre for International Agricultural Research (ACIAR), Canbera.

25. Islam MR, Huque QME, Giasuddin M, Alam J and Rahman MM. 2003. Assessment of Maternal derived antibody of commercial flock against Newcastle disease. Proceedings of 3rd International Poultry Show and Seminar, Bangladesh China Friendship Conference Center, Dhaka, Bangladesh.

26. Beard CW, Villegas P and Glisson JR. 1993. Comparative efficacy of the B-1 and VG/GA vaccine strains against velogenic viscerotropic Newcastle disease virus in chickens. Avian Dis. 37: 222-225.

27. Mahmud MS. 2006. Comparative efficacy of Avinew ${ }^{\circledR}$ (VG/GA strain) and BCRDV (F strain) vaccines in broiler chicks. MS Thesis. Department of Microbiology and Hygiene, Bangladesh Agricultural University (BAU), Mymensingh.

28. Schmidt U and Schmidt D. 1955. Connection between hemagglutination inhibiting antibodies and immunity after vaccination against Newcastle disease. Arch Exp Vet Med. 9: 505-516.

29. Al-Garib SO, Gielkens ALJ and Koch G. 2003. Review of Newcastle disease virus with particular references to immunity and vaccination. World Poul Sci J. 59: 185-197.

30. Barua SR, Amin MM, Islam S, Chowdhury S, Khan MSI and Asgar MA. 2008. Evaluation of Antibody Production against Newcastle Disease Virus after Immunization with Different Vaccines in Fayoumi Chicks. Bang J Microbiol, 25 (1): 31-35. 